\title{
Zinc solubilizing plant growth promoting microbes produce zinc nanoparticles
}

\section{Uzma Sultana, Suseelendra Desai, Gopal Reddy \& Prasad TNVKV}

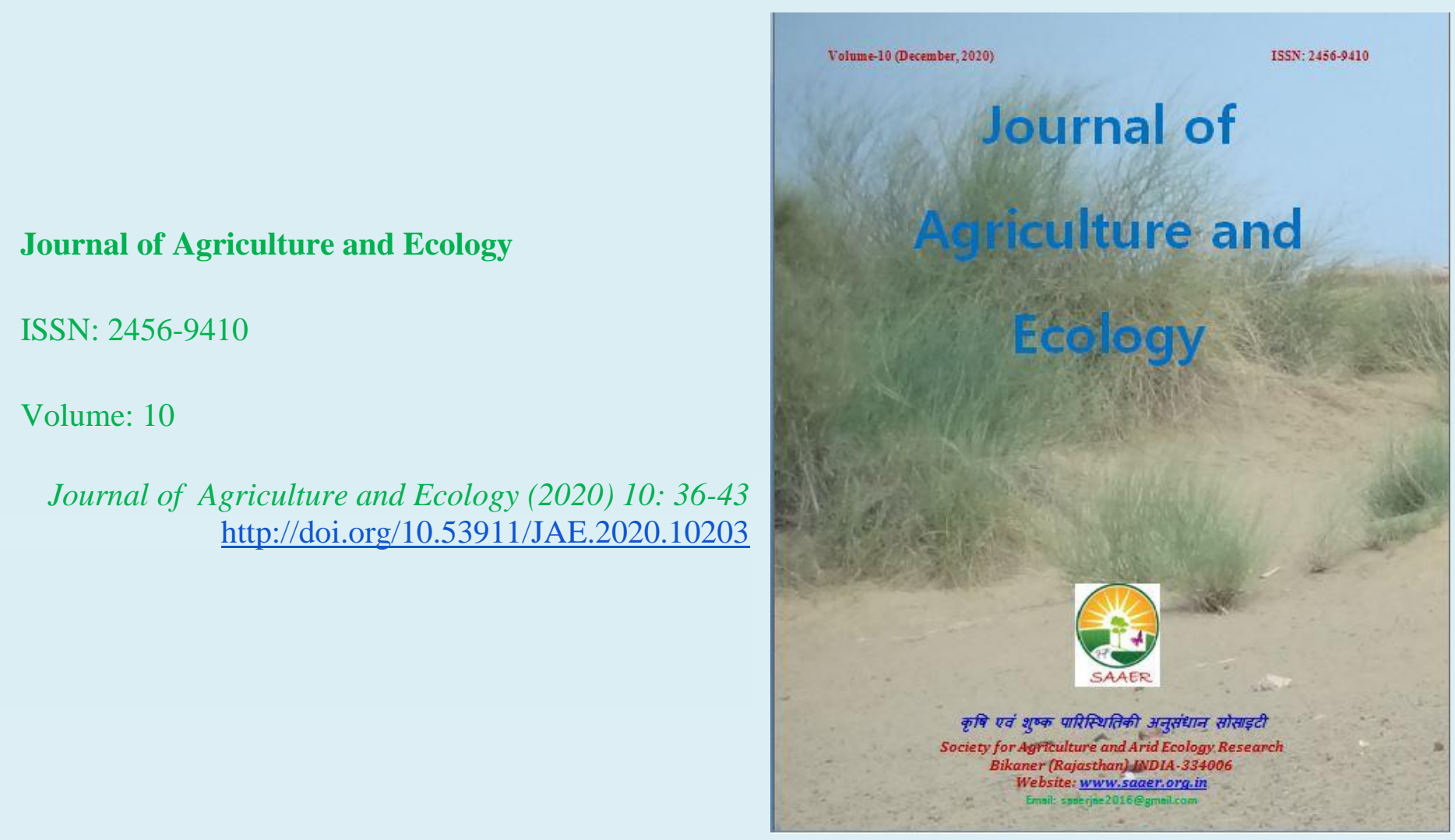


Zinc solubilizing plant growth promoting microbes produce zinc nanoparticles

\author{
Uzma Sultana ${ }^{l}$, Suseelendra Desai ${ }^{1} \square$, Gopal Reddy ${ }^{2}$ \& Prasad TNVKV
}

${ }^{I}$ Division of Crop Sciences, Central Research Institute for Dryland Agriculture, Santoshnagar, Hyderabad - 500059, India

${ }^{2}$ Department of Microbiology, Osmania University, Hyderabad 500007, India

${ }^{3}$ Institute of Frontier Technology, RARS, Acharya NG Ranga Agricultural University, Tirupati - 517502, India

Corresponding author: Suseelendra Desai,E-mail: desai1959@yahoo.com

Article Info

Article history

Received: 28 September 2020

Accepted: 29 November 2020

Available online: 31 December 2020

Key Words: Zinc Nano Particles, Pseudomonas, Bacillus, Azospirillum, FTIR, Zeta Potential, $\mathrm{ZnO}, \mathrm{ZnCO}_{3}$.
Abstract
Strains of Pseudomonas, Bacillus, and Azospirillum with plant growth promoting ability were checked for their zinc solubilizing ability at ICARCRIDA, Hyderabad, India. Efficient zinc solubilizing microorganisms were evaluated for their ability to produce nano-scale zinc particles. The nanoparticles from the cell-free culture filtrates obtained from these strains were characterized for particle size, Zeta potential and functional groups. Presence of $\mathrm{Zn}$ nanoparticles in the bacterial culture filtrate was confirmed by particle distribution and Scanning electron microscope (SEM) analysis. Most properties of nanoparticles are size dependent. Zinc nanoparticles were observed to be spherical in shape and size ranged from 52.0 to $106.0 \mathrm{~nm}$. Zeta potential of the $\mathrm{Zn}$ nanoparticles was estimated to understand the stability of the particles. The measured zeta potentials varied from $14.5 \mathrm{mV}$ to $+179.10 \mathrm{mV}$ indicating high stability and dispersion of the zinc nanoparticles. FTIR peaks at different wave numbers depicted the role of functional groups of proteins in the biosynthesis of $\mathrm{Zn}$ nanoparticles. These results demonstrate the green synthesis of zinc nanoparticles by the plant growth promoting and zinc solubilizing strains of Azospirillum, Pseudomonas and Bacillus.

Copyright (C2020 Uzma Sultana et al., This is an open access article published under the terms of the Creative Commons Attribution License, which permits unrestricted use, distribution, and reproduction in any medium, provided the original work is properly cited.

Preferred citation: Uzma Sultana, Suseelendra Desai, Gopal Reddy \& Prasad TNVKV. 2020. Zinc solubilizing plant growth promoting microbes produce zinc nanoparticles. Journal of Agriculture and Ecology, 10: 36-43; http://doi.org/10.53911/JAE.2020.10203.

\section{Introduction}

Zinc $(\mathrm{Zn})$ is one of the vital minerals required for optimum plant growth as well as animals, including human beings such as mental retardations, impairments of the immune system and overall poor health. In recent years, the $\mathrm{Zn}$ deficiency problem has received increasing attention and appears to be the most serious micronutrient deficiency together with vitamin A deficiency especially 
among children. It plays a vital role in biochemical reactions in plants and its deficiency is displayed as a remarkable reduction in plant height and develops whitish-brown patches that turn necrotic subsequently (Singh 1999). In India, $>50 \%$ of agro-ecosystems are $\mathrm{Zn}$ deficient, especially the Indo-Gangetic plains spanning across the States of Punjab and Uttar Pradesh. Overall, zinc deficiency in the country has increased from $42 \%$ to $49 \%$ in the past four decades and it is expected to increase up to $63 \%$ by 2025 (Singh 2009). Plant response to Zn deficiency occurs in terms of membrane integrity loss, reduced synthesis of metabolites and susceptibility to heat stress (Bhupinder et al., 2005). $\mathrm{Zn}$ is supplemented exogenously to plants in the form of chemical fertilizers like zinc sulphate that subsequently transforms (96-99\%) into different insoluble forms depending upon the soil types, physicochemical reactions. However, external supplementation of micronutrients is not only expensive, but also leads to unwanted accumulation of them in the soil in fixed forms. Bacteria-mediated solubilization of zinc has been widely studied in fungi and bacteria (Suseelendra Desai et al. 2012).

Decreased particle size resulted in increased number of particles per unit weight of applied $\mathrm{Zn}$ and increase in the specific surface area of a fertilizer (Mortvedt 1992). Nanoparticles of $\mathrm{Mg}, \mathrm{Zn}, \mathrm{Fe}$ and $\mathrm{P}$ are the structural component of enzymes (phosphatases and phytase), polysaccharides and chlorophyll. These nanoparticles can be tagged to agrochemicals or other substances as delivery agent to plant system and tissues for controlled release of chemicals. Nanoparticles with small size and large surface area are expected to be the ideal candidates for use as a Zn fertilizer in plants (Prasad et al. 2012). First evidence of biosynthesis of nanoparticles was reported using Pseudomonas stulzeri where the nanoparticles were deposited on the cell membrane (Klaus et al. 1999). Subsequently, Lactobacillus strains (Ahmad et al. 2003); Fusarium oxysporum (Minaeian et al. 2008); Bacillus subtilis (Nair et al. 2002); Cornybacterium sp. (Saifuddin et al. 2009); Klebsiella pneumonia (Zhang et al. 2005), and Escherichia coli (Gurunathan et al. 2009) have been found to produce nanoparticles. On the other hand, E. coli was shown to be involved in extra- and intra-cellular synthesis of nanoparticles (Gurunathan et al. 2009). However, very few reports suggest synthesis of $\mathrm{Zn}$ nanoparticles by plant growth promoting microorganisms. In the present study, we report the ability of $\mathrm{Zn}$ solubilizing rhizobacteria to produce $\mathrm{Zn}$ nanoparticles.

\section{Materials and Methods}

Bacterial strains used in this study were obtained from the culture bank of ICARCentral Research Institute for Dryland Agriculture, Hyderabad. Based on previous qualitative and quantitative screening, five efficient zinc solubilizing strains viz. Bacillus B116, Pseudomonas P29, Pseudomonas P33, and Azospirillum 20 were selected for nanoparticle analysis [6]. All the isolates were grown in Minimal salt medium amended with $0.1 \% \mathrm{ZnO}$ with an initial population containing $2 \times 10^{8} \mathrm{CFU} / \mathrm{ml}$ and incubated at room temperature in an orbital shaking incubator with $180 \mathrm{rpm}$ speed. The culture medium was centrifuged after $72 \mathrm{~h}$ of inoculation and the supernatant was collected. 
Supernatant was analysed for the presence of nanoparticles in nanoparticle analyzer.

Ten $\mathrm{ml}$ of the supernatant was transferred to a cuvette and placed into the nanoparticle analyzer (Horiba Nanoparticula 100). Three replicas for each sample were maintained respectively. Each sample was read three times and the mean was considered as particle size. The zeta potentials were recorded using Particle size analyzer (Horiba Nanoparticula 100, Japan). This apparatus uses Dynamic Light scattering (DLS) phenomenon. The sample holder temperature was maintained at $25^{\circ} \mathrm{C}$, a technique used to determine the stability profile of small particles in solution. Nano scale Zinc particles were observed under SEM. To observe nanoparticles of Zinc, $10 \mu \mathrm{l}$ of the suspension was spotted on to the metal slide. Metal slide was placed inside a desiccator over night to remove moisture completely. After removing the slide from the desiccator, a gold sputtering of approximately $1 \mathrm{~nm}$ was done over the suspension.

For Fourier Transform Infra Red (FTIR) spectroscopy measurement, the biotransformed product present in cell-free filtrate was analyzed. FTIR spectrum (Bruker Tensor 27, USA) was recorded in mid IR region in the range of 400-4000 wavenumber $\mathrm{cm}^{-1}$. A drop of the sample solution was carefully added to the potassium bromide crystals using a micropipette and the spectrum was recorded in transmittance $(\%)$ mode.

\section{Results and Discussion}

Plant growth promoting strains of Pseudomonas, Bacillus and Azospirillum found to solubilize $\mathrm{ZnO}$ and $\mathrm{ZnCO}_{3}$ were formulated and field-evaluated. While trying to understand their mode of action of $\mathrm{Zn}$ solubilization, it was found that these strains synthesized $\mathrm{Zn}$ nanoparticles in vitro when cultured in MS broth supplemented with $\mathrm{ZnO}$ or $\mathrm{ZnCO}_{3}$. The results of the particle size distribution (PSD) dynamic light scattering method conforms the presence of Zinc nanoparticles. In comparison to control, in all treatments, the Z-Average particle size was 10.5 to 14.6 times smaller than control. Smallest particle size was observed in P29 treatment. However, the treatments did not differ significantly (Table 1).

Table1. Particle Z-Average size and Poly dispersity index of $\mathrm{Zn}$ nanoparticles produced by different bacterial strains in $\mathrm{ZnO}$ incorporated broth

\begin{tabular}{lll}
\hline Strains & $\begin{array}{l}\text { Z-Average } \\
\text { particle size } \\
(\mathrm{nm})\end{array}$ & $\begin{array}{l}\text { Poly } \\
\text { dispersity } \\
\text { Index }\end{array}$ \\
\hline B116 & 593.0 & 0.60 \\
P 29 & 428.8 & 0.51 \\
P 33 & 482.0 & 0.37 \\
Asp 20 & 539.0 & 0.48 \\
Control & 6279 & 1.00 \\
\hline
\end{tabular}

Electron Microscopy (SEM) analysis image provided further insight into the shape size, morphology and distribution of nanoparticles. The SEM micrographs showed uniformly distributed spherical or roughly spherical nanoparticles. The size of the $\mathrm{Zn}$ nanoparticles ranged from 106 to $52 \mathrm{~nm}$. In control the size was 5200nm (Fig 1). 


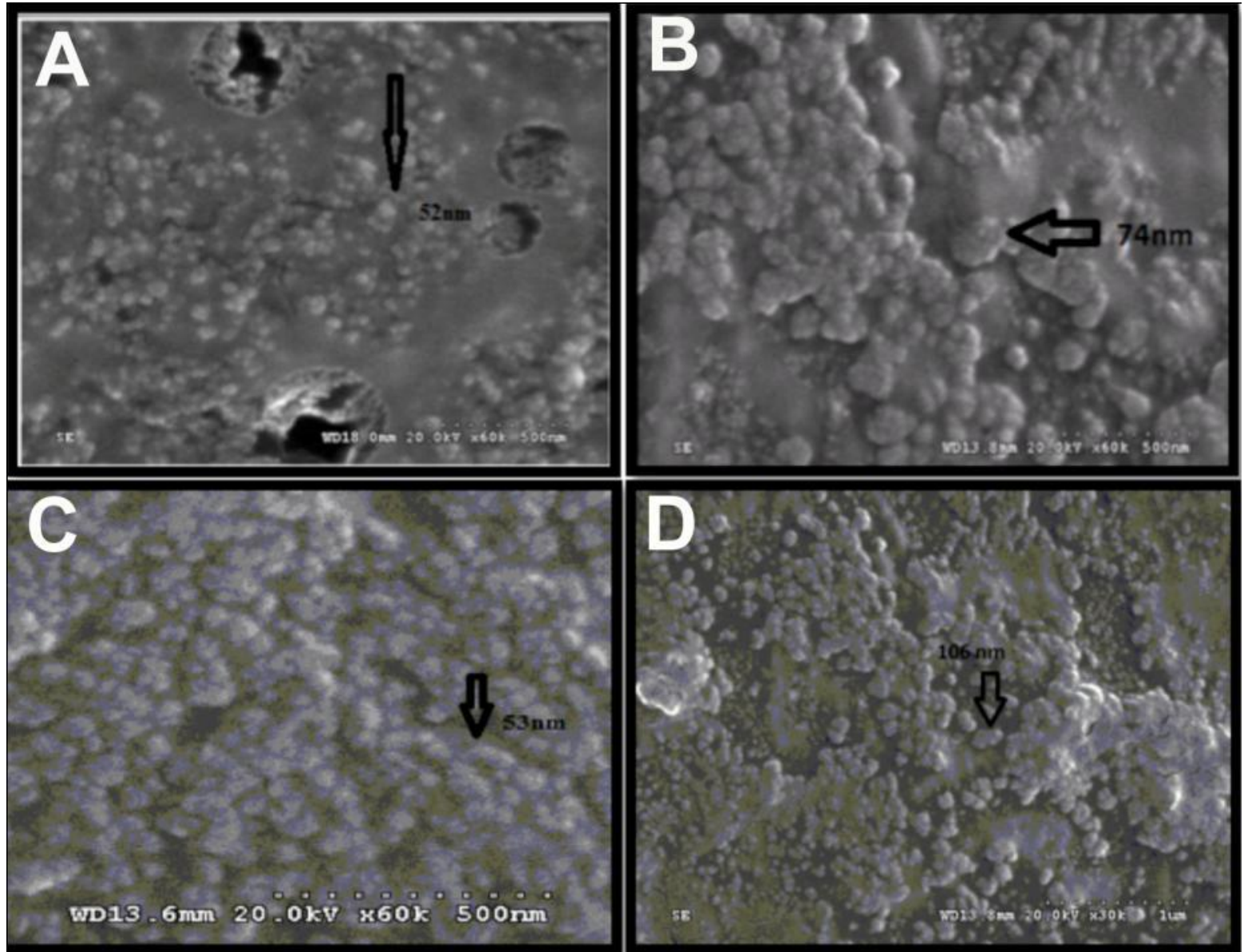

Fig 1. SEM image of Nanoparticles of zn produced by a) P 29 (52nm) b) P 33 (74nm) c) Asp 20 $(53 \mathrm{~nm}) \mathrm{d}) \mathrm{B} 116(106 \mathrm{~nm})$ in media amended with $1 \mathrm{ppm} \mathrm{ZnO}$.

There were differences among the strains in synthesizing different sizes of zinc nanoparticles. According to particle size distribution and SEM analysis, Pseudomonas putida P29 produced smallest zinc nanoparticles of the size $52 \mathrm{~nm}$ followed by Asp20 and B116 produced large particles (106 $\mathrm{nm}$ ) as against control where the particle size was $5200 \mathrm{~nm}$. All treatments did not differ significantly as compared to control indicating that nanoparticles produced by all organisms were within a range. Using the nano-particle analyzer, the Zeta potential was measured as the magnitude of Zeta Potential $(-200 \mathrm{mV}$ to $+200 \mathrm{mV}$ ) gives an indication of the potential stability of the colloidal system. The Zeta potentials of $\mathrm{Zn}$ nanoparticles produced by B116, P33, P29 and Asp20 were $+179.1 \mathrm{mV}$, $14.5 \mathrm{mV},+0.5 \mathrm{mV}$ and $0.5 \mathrm{mV}$, respectively, clearly indicating the stability of the nanoparticles (Fig 2). 

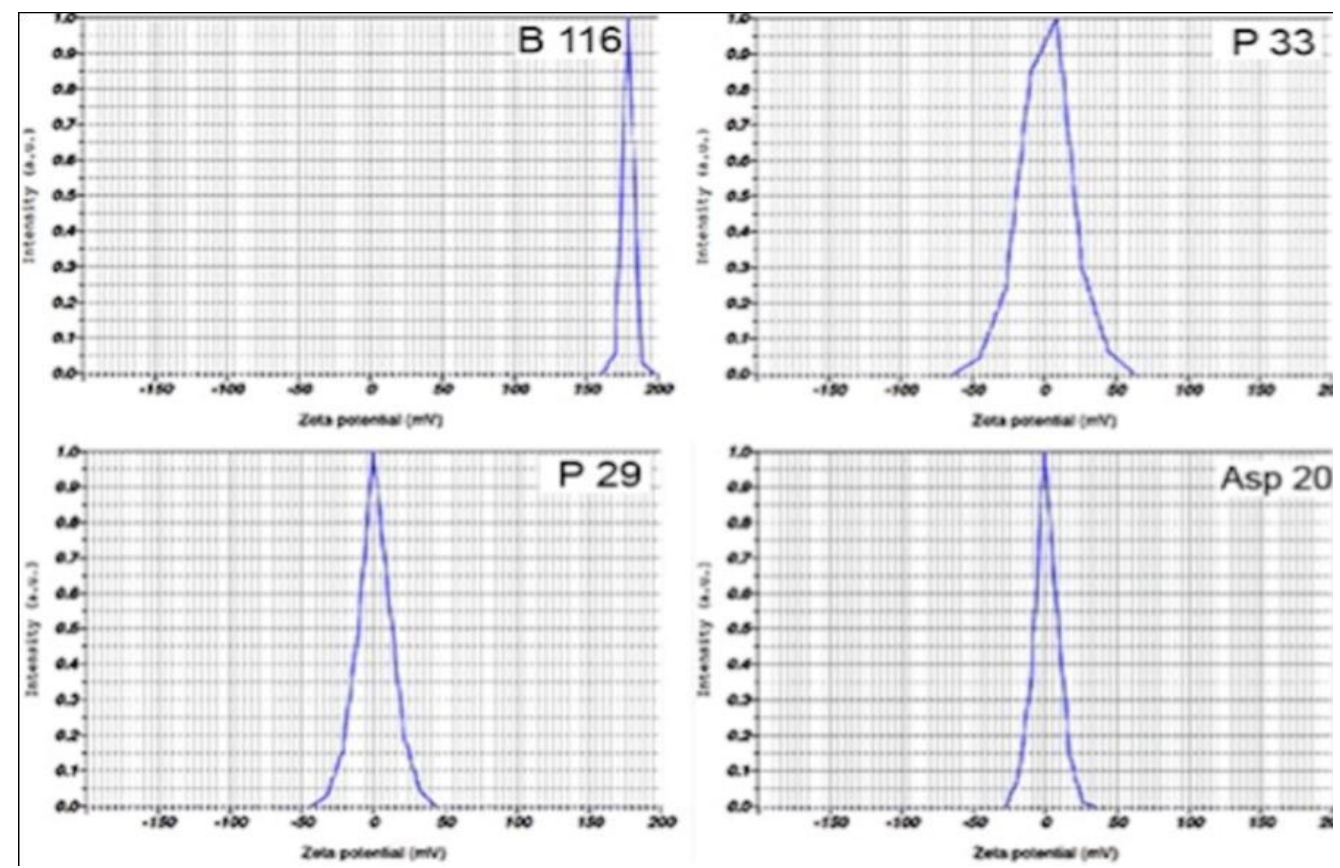

Fig 2. Zeta potential of Zn nanoparticles produced by B116 (+179.1 mV), P33 (-14.5 mV), P29 $(+0.5 \mathrm{mV})$, Asp $20(+0.8 \mathrm{mV})$, and in $\mathrm{ZnO}$ amended MS medium

FTIR analysis of the cell-free culture filtrates bioactive molecules enabling synthesis and of $\mathrm{ZnO}$ amended $\mathrm{MS}$ medium was done to stabilization of $\mathrm{Zn}$ nanoparticles (Fig 3). identify the interactions between $\mathrm{Zn}$ and

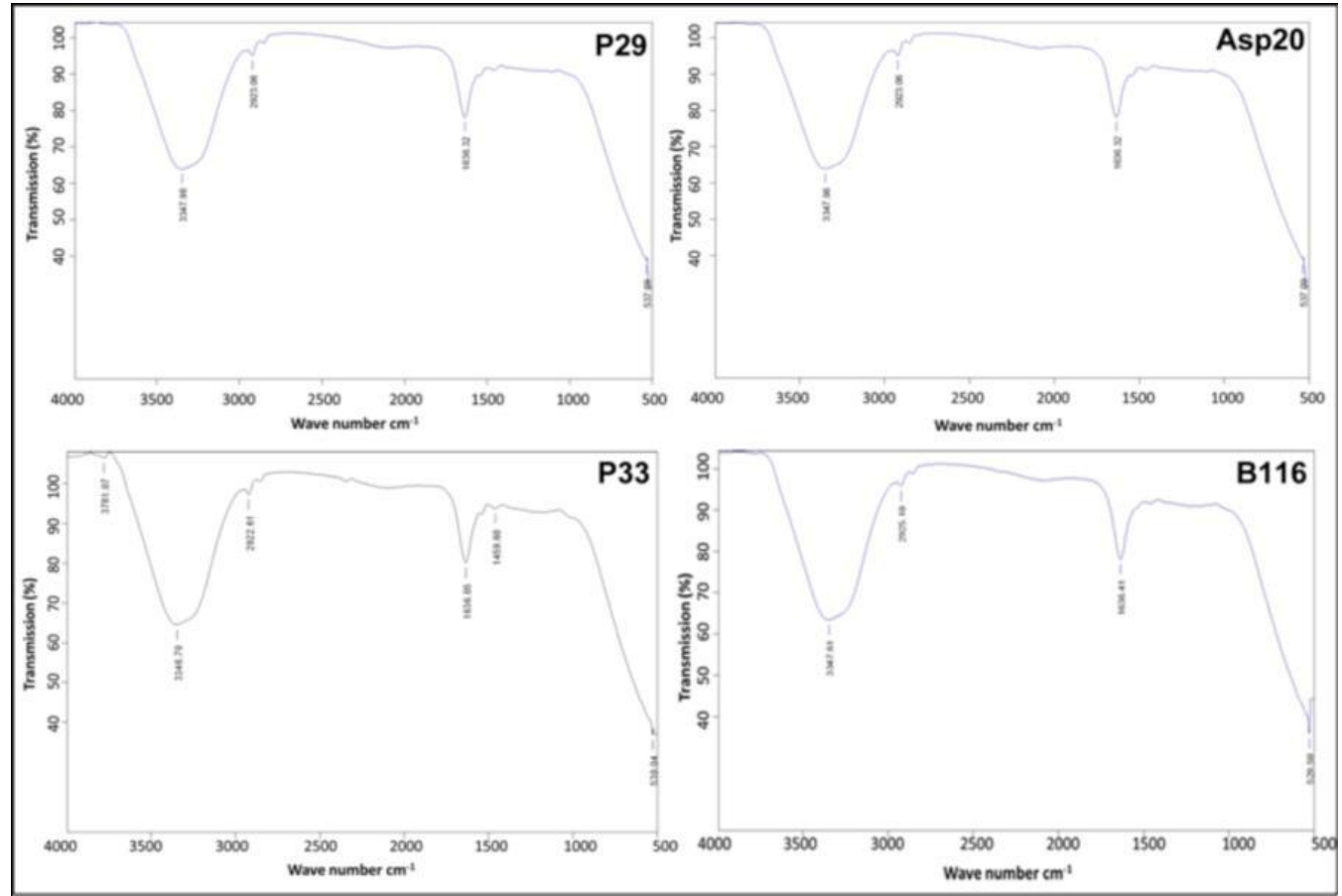

Fig 3. IR spectrum of cell-free culture filtrates of $\mathrm{ZnO}$ amended $\mathrm{MS}$ medium inoculated with different strains of bacteria 
The FTIR spectra of cell-free extracts of $\mathrm{ZnO}$ amended $\mathrm{MS}$ medium showed prominent peaks at 3346, 2923, 1636, 1459 and 538 wave numbers $\mathrm{cm}^{-1}$. The strong broad wave at $3346 \mathrm{~cm}^{-1}$ is attributed to $\mathrm{NH}$ stretch of amides. The wave observed at $2923 \mathrm{~cm}^{-1}$ is stretch vibration of primary and secondary amides of protein. The band observed at 1636 $\mathrm{cm}^{-1}$ is assigned to the bending vibrational mode of amides. The peaks at 1459 refer to amino and amino-methyl stretching groups of protein. Peak observed at $529 \mathrm{~cm}^{-}{ }^{1}$ corresponds to the stretching vibrations of $\mathrm{Zn}$ nanoparticles.

The exact mechanism for the synthesis of nanoparticles using biological agents has not yet been elucidated but it has been suggested that various biomolecules are responsible for the synthesis of nanoparticles. The mechanism of extracellular biosynthesis of nanoparticles is proposed as a reductasemediated reaction, which brings about bioreduction of metal ions and synthesizes nanoparticles (Honary et al. 2012). In the present study, FTIR spectrum of the nanoparticles indicated the presence of various chemical groups, one of which is an amide. An amide I band was observed at 1636 wavecm $^{-1}$, which is the bending vibrational mode of amides. The stretching band of amide at 3346 wavecm $^{-1}$ further confirmed this result. The 1636 wave $\mathrm{cm}^{-1}$ corresponds to amide I due to carbonyl stretch in proteins. FTIR spectrum showed the presence of functional groups such as amide linkages and - COO-, possibly between amino acid residues in protein and the synthesized $\mathrm{Zn}$ nanoparticles. Similar results supporting the interactions between the proteins and nanoparticles during the biosynthesis were reported (Honary et al. 2012). Surface properties of the nanoparticles are known to be one of the most important factors that govern their stability and mobility as colloidal suspensions, or their adsorption or aggregation and deposition. Zeta potential can be related to the stability of colloidal dispersions as it indicates the degree of repulsion between adjacent and similarly charged particles in dispersion and high zeta potential values indicate high stability and with decrease in the particle size, the stability also decreases (Vielkind et al. 2013). Highest zeta potential of $+179.10 \mathrm{mV}$ was observed for the particle size $106.0 \mathrm{~nm}$ produced by B116 indicating best stability. However, nanoparticles with zeta potential values greater than $+25 \mathrm{mV}$ and $-25 \mathrm{mV}$ typically are stable (Sonika et al., 2015). Hence, it could be inferred that the nanoparticles produced with lower zeta potentials such as $+0.5 \mathrm{mV}$ may not be stable even though they are only $52 \mathrm{~nm}$. Further, low stability nanoparticles tend to form aggregates in the medium, which is influenced by various factors. Aggregation of metal oxide nanoparticles in aqueous solutions depends on ionic strength, $\mathrm{pH}$, surface charge and charge density (Domingos et al., 2009; Guzman et al. 2006). In the present study also, such aggregation was noticed in cases where the zeta potential was low. Poly dispersity index was lowest in P33 treatment whereas it was highest in B116 (Table 1). However, all the treatments did not differ significantly as against control. Results of particle size distribution clearly indicated that the obtained Zinc nanoparticles are both mono- and polydispersed in nature towards as the values 
ranged from 0.37 to 0.60 across treatments. Generally samples with very broad distribution size have $>0.70$ poly-dispersity index and thus while studying extracellular synthesis of $\mathrm{ZnO}$ nanoparticles, an average particle Z-Average size of $46.61 \mathrm{~nm}$ and Poly dispersity index of 0.552 was also considered as mono-dispersed in nature (Nagarajan \& Kuppusamy 2011).

\section{Conclusion}

The present study clearly shows that $\mathrm{Zn}$ nanoparticles are produced by $\mathrm{Zn}$ solubilizsing strains of Pseudomonas, Bacillus and Azospirillum spp. These results open a new field for exploration as to mode of uptake of nutrients by the plants vis-à-vis role of plant growth promoting rhizomicroorganisms. Similar experiments also could be planned for other microbe-mediated plant nutrient supplementation studies to understand the dynamics of crop nutrition.

\section{Acknowledgements}

The authors sincerely thank Director, ICAR-CRIDA for his constant support and encouragement to conduct this research at CRIDA. Senior author also acknowledges the fellowship from UGC (MANF scheme) and Dr. B. Suresh ARCI Hyderabad for providing research facilities.

\section{References}

Ahmad A, Mukherjee P, Senapati S, Mandal D, Khan MI, Kumar R \& Sastry M. 2003. Extracellular biosynthesis of silver nanoparticles using the fungus Fusarium oxysporum. Coll Surf, 28:313-18.

Bhupinder S, Senthil AN, Singh BK \& Usha K. 2005. Improving zinc efficiency of cereals under zinc deficiency. Current Science, 88:36-44.
Domingos RF, Tufenkji N \& Wilkinson KI. 2009. Aggregation of titanium dioxide nanoparticles: role of a fulvic acid. Environmental Science Technology, 43:1282-6.

Gurunathan S, Kalishwaralal K, Vaidyanathan R, Venkataraman D, Pandian SRK, Muniyandi J, Hariharan N \& Eom SH. 2009. Biosynthesis, purification and characterization of silver nanoparticles using Escherichia coli. Colloids Surf B, 741:328-35.

Guzman KAD, Finnegan MP \& Banfield JF. 2006. Influence of surface potential on aggregation and transport of Titania nanoparticles. Environmental Science Technology, 24:7688-7693.

Honary S, Gharaei-Fathabad E, Paji ZK \& Eslamifar, M. 2010. A Novel Biological Synthesis of Gold Nanoparticle by Enterobacteriaceae Family. Tropical Journal of Pharmacology Research, 6:887-891.

Klaus $\mathrm{T}$, Joerger R, Olsson E \& Granqvist CG. 1999. Silver based crystalline nanoparticles, microbially fabricated. Proceeding of National Academy Science USA, 96:13611-13614.

Minaeian S, Shahverdi AR, Nohi AS \& Shahverdi HR. 2008. Extracellular biosynthesis of silver nanoparticles by some bacteria. J Sci IAU, 17:1-4.

Mortvedt JJ. 1992. Crop response to level of water-soluble zinc in granular zinc fertilizers. Fertilizer Research, 33:24955.

Nagarajan S \& Kuppusamy KA. 2011. Extracellular synthesis of zinc oxide nanoparticle using seaweeds of gulf of 
Mannar, India. Journal of Nanobiotechnology, 11:39-50.

Nair B \& Pradeep T. 2002. Coalescence of nanoclusters and formation of submicron crystallites assisted by Lactobacillus strains. Cryst Growth Des, 2:293-98.

Prasad TNVKV, Sudhakar Y, Sreenivasulu P, Latha V, Munaswamy K, Raja Reddy TS, Sreeprasad PR, Sajanlal \& Pradeep T. 2012. Effect of nanoscale zinc oxide particles on the germination, growth and yield of peanut. Journal of Plant Nutrition, 6:905-927.

Saifuddin N, Wong CW, \& Nuryasumira AA. 2009. Rapid biosynthesis of silver nanoparticles using culture supernatant of bacteria with microwave irradiation. $\mathrm{E}$ J Chem, 6:61-70.

Singh AL. 1999. Mineral nutrition of groundnut. In: Hemantharajan A, editor. Advances in Plant Physiology (pp 161200). Jodhpur, India: Scientific Publications.

Singh MV. 2009. Micronutrient nutritional problems in soils of India and Improvement for human and animal health. Indian Journal of Fertilizers, 5:11-26.

Sonika K, Jigmet L, Sumit S \& Haq Nawaz Sheikh. 2015. Green hydrothermal synthesis and optical properties of cGd2S3 nanoparticles. Applied Nan science, DOI 10.1007/s13204-015-04787.

Suseelendra Desai, Praveen Kumar G, Uzma Sultana, Sravani Pinisetty, Mir Hassan Ahmed SK, Leo Daniel Amalraj E \& Gopal Reddy. 2012. Potential microbial candidate strains for management of nutrient requirements of crops. African Journal of Microbiological Research, 6: 3924-3931

Vielkind M, Kampen I \& Kwade A. 2013. Zinc Oxide Nanoparticles in bacterial growth medium Optimized dispersion and growth Inhibition of Pseudomonas putida. Adv Nanoparticles, 2:287-293.

Zhang H, Li Q, Lu Y, Sun D, Lin X \& Deng $\mathrm{X}$. Biosorption and bioreduction of diaminesilver complex by Corynebacterium. J Chem Technol Biotechnol, 80: 285-290. 